\title{
Characterization of a Glycoside Hydrolase Family 50 Thermostable $\beta$-agarase AgrA from Marine Bacteria Agarivorans sp. AG17
}

\author{
Chamilani Nikapitiya ${ }^{1}$, Chulhong $\mathrm{Oh}^{2}$, Youngdeuk Lee ${ }^{1}$, Sukkyoung Lee ${ }^{1}$, \\ Ilson Whang ${ }^{3}$ and Jehee Lee ${ }^{1,4 *}$ \\ ${ }^{1}$ Department of Marine Life Sciences, Jeju National University, \\ Jeju 690-756, Korea \\ ${ }^{2}$ Korea Ocean Research \& Development Institute, Ansan 426-744, Republic of Korea \\ ${ }^{3}$ Department of Life Science, Jeju National University, \\ Јеju 690-756, Korea \\ ${ }^{4}$ Marine and Environmental Institute, Jeju National University, \\ Јеju 690-814, Korea
}

\begin{abstract}
An agar-degrading Agarivorans sp. AG17 strain was isolated from the red seaweed Grateloupia filicina collected from Jeju Island. A beta-agarase gene from Agarivorans sp. AG17 was cloned and designated as agrA. agrA has a 2,985 bp coding region encoding 995 amino acids and was classified into the glycoside hydrolase family (GHF)-50. Predicted molecular mass of the mature protein was $105 \mathrm{kDa}$. His-tagged agrA was overexpressed in Escherichia coli and purified as a fusion protein. The enzyme showed $158.8 \mathrm{unit} / \mathrm{mg}$ specific activity (optimum temperature at $65^{\circ} \mathrm{C}$ and $\mathrm{pH} 5.5$ in acetate buffer) with unique biochemical properties (high thermal and $\mathrm{pH}$ stabilities). Enzyme produced neoagarohexaose, neoagarotetraose and neoagarobiose by degrading agar, and hydrolyzed neoagaro-oligosaccharides were biologically active. Hence the purified enzyme has potential for use in industrial applications such as the development of cosmetics and pharmaceuticals.
\end{abstract}

Key words: Agarivorans sp., Beta agarase, GHF-50, Neoagaro-oligosaccharides, Thermostable

\section{Introduction}

Agar is the most abundant polysaccharide found in the cell walls of many red seaweeds and is composed of agarose and agaropectin. Agarose is composed of alternating residues of 3 - $O$-linked $\beta$-D-galactopyranose and 4-O-linked 3,6-anhydro- $\alpha$-L-galactose (Duckworth and Yaphe, 1971). Even though agaropectin is composed of the same disacchariderepeating units, sulfoxy or methoxy and pyruvate residues can replace some of the hydroxyl groups of 3,6-anhydro- $\alpha$-L-galactose residues (Araki, 1966).

Agarase is the enzyme which hydrolyzes agarose. Agarase-producing organisms have been reported from marine and other environments. However, most of the known agarolytic organisms are bacteria (Zhang and Sun, 2007). Those include Microbulbifer sp. (Ohta et al., 2004a.; Ohta et al., 2004b), Cytophaga sp. (Van der Meulen and Harder, 1975)

\footnotetext{
*Corresponding author: jehee@jejunu.ac.kr
}

Agarivorans sp. (Fu et al., 2008b; Lee et al., 2006; Ohta et al., 2005), Pseudomonas sp. (Groleau and Yaphe, 1977; Ha et al., 1997; Lee et al., 2000; Morrice et al., 1983; Ryu et al., 2001) Pseudoalteromonas sp. (Ma et al., 2007; Schroeder et al., 2003; Vera et al., 1998), Alteromonas sp. (Hassairi et al., 2001; Potin et al., 1993; Wang et al., 2006) Streptomyces sp. (Kendall and Cullum, 1984), Vibrio sp. (Aoki et al., 1990; Fu et al., 2008a; Sugano et al., 1993a; Sugano et al., 1993b), Zobellia sp. (Allouch et al., 2003; Jam et al., 2005), Microscilla sp. (Naganuma et al., 1993) and Saccharophagus sp. (Ekborg et al., 2006). To date, some of the agarases have been purified and characterized. These enzymes show a high degree of heterogeneity in terms of their amino acid sequence, molecular masses, catalytic properties and substrate specificities. However, the identified $\beta$-agarases are functionally similar by hydrolyzing $\beta$-1,4-linkages in the agar substrate (Ohta et al., 2004b). 
Based on the mode of action, agarases have been divided into $\alpha$-agarase and $\beta$-agarase enzymes. $\alpha$ agarase hydrolyzes $\alpha-1,3$-linkages of agarose, resulting in agaro-oligosaccharides such as agarobiose (Young et al., 1978), while $\beta$-agarase hydrolyzes $\beta$ 1,4-linkages in agarose (Duckworth and Turvey, 1969), resulting neoagaro-oligosaccharides such as neoagarohexaose, neoagarotetraose and neoagarobiose as the main products (Zhang and Sun, 2007). Most of the agarases that have been isolated and characterized belong to the $\beta$-agarases. Based on the amino acid sequence similarity, all of the $\beta$-agarases have been classified into three glycoside hydrolase families (GHFs) 16, 50 and 86 (http://afmb.cnrsmrs.fr/CAZY/).

Many potential applications in the food, cosmetics, medical and other industries have been reported for the agarases, which produce oligosaccharides from agar or agarose (Kobayashi et al., 1997; Yoshizawa et al., 1995). Since agarase has ability to degrade the cell wall of seaweeds, it has potential to be used for the extraction of a variety of labile substances with bioactive compounds, and in addition, can be used for the preparation of protoplasts (Araki and Morishita, 1998). It has been reported that AgaA (GHF-50) from a Vibrio strain degrades agarose as well as agarooligosaccharides containing four sugars to yield neoagaro-biose (Sugano et al., 1993a) and possesses a whitening effect that can be applied in the cosmetic industry (Kobayashi et al., 1997). Some GHF-16 agarases promoted degradation of agarose and agarooligosaccharides containing six sugars to yield neoagaro-tetraose as main products (Schroeder et al., 2003).

Due to the diversification of $\beta$-agarase-producing bacteria and their agarase enzyme characteristics, further studies on biochemical and genetic variations of newly isolated strains producing these enzymes as well as on the enzymes of already identified bacterial strains are important. Ohta et al. reported agarases from Agarivorans sp. which belongs to GHF-50 with similar enzymatic properties (Ohta et al., 2004a; Ohta et al., 2004b). In the present study described herein, an agar-degrading bacteria Agarivorans sp. AG17 was isolated from a marine environment. The agrA was cloned, overexpressed in Escherichia coli, and the recombinant protein was purified. Finally, biochemical characterization of purified agarase (AgrA) and functional activity studies of neoagaro-oligosaccharides obtained from agar hydrolysates were conducted to assess the suitability of developing pharmaceutical and cosmetic products from this product.

\section{Materials and Methods}

\section{Isolation and identification of agarase-producing bacteria strains}

A strain of the Agarivorans sp. was isolated from the seaweed, Grateloupia filicina collected at the south coast of Jeju Island, Republic of Korea. The seaweeds were macerated and diluted with autoclaved sea water. Diluted samples were plated on $1.5 \%$ agar in seawater plates (SW) in order to screen agarase-producing bacteria. As another screening method, different seaweeds were maintained and grown on separate selection plates. The plates were incubated at $30^{\circ} \mathrm{C}$ for 3-5 days. Positive colonies having pits or clear zones were picked out and streaked on $0.3 \%$ tryptone and $1.5 \%$ agar in seawater (SWT), $0.3 \%$ yeast extract and $1.5 \%$ agar in seawater (SWY) and marine agar plates (Difco, Detroit, MI). Then, the plates were incubated at $30^{\circ} \mathrm{C}$ for $2-4$ days. The pure colonies were selected under same conditions and inoculated in SWT, SWY and marine broth including $0.2 \%$ agar, then incubated at $30^{\circ} \mathrm{C}$. The stock was prepared from the grown bacteria using $20 \%$ glycerol; samples were kept at $-70^{\circ} \mathrm{C}$.

\section{Identification of bacteria using 16S rDNA sequence analysis}

Cultured bacteria cells were collected from growth medium by centrifugation at $15,000 \mathrm{rpm}$ for $5 \mathrm{~min}$. Genomic DNA was isolated using Accuprep genomic DNA extraction kit (Bioneer, Korea) following the manufacturer's instructions. Polymerase Chain Reaction (PCR) was carried out for $16 \mathrm{~S}$ rDNA sequence amplification. Isolated genomic DNA was used as a template and universal primers $(16 \mathrm{~S}-27 \mathrm{~F}$ as forward and $16 \mathrm{~S}-1492 \mathrm{R}$ as reverse) were used for 16S rDNA sequence amplification, shown in Table 1. The sequences were analyzed using the software NCBI Blast N, and DNassist version 2.2.

\section{PCR amplification of the agrA from Agarivorans sp. AG17}

For the amplification of an agarase gene from the identified strain, $\mathrm{AgF} 1$ forward primer and AgR2 reverse primer were designed using other known Agarivorans sp. agarase sequences from the NCBI database (Table 1). The PCR mixture included $5 \mu \mathrm{L}$ 10x Ex Taq polymerase buffer, $4 \mu \mathrm{L}$ of $2.5 \mathrm{mM}$ dNTP, $100 \mathrm{pmol}$ of each primers, 400-600 ng of genomic DNA as template, and 3 units of Ex Taq DNA polymerase in $50 \mu \mathrm{L}$ reaction volume. In the PCR reaction the initial denaturation step was carried out at $94^{\circ} \mathrm{C}$ for $5 \mathrm{~min}$ and amplification was carried out 
Table 1. Primers used in this study

\begin{tabular}{lll}
\hline Name & Object & Sequence (5' to 3' direction) \\
\hline 16s-27F & 16s rDNA sequence amplification & AGAGTTTGATCMTGGCTCAG \\
16s-1492R & 16s rDNA sequence amplification & TACGGYTACCTTGTTACGACTT \\
AgF1 & agrA gene amplification & ATGAAGATTAAATTTTTATCTGCAGC \\
AgR2 & agrA gene amplification & TTACACTTTACGACGTCTTAG \\
AgF3 & ORF amplification & $(\text { GA })_{3}$ CATATGGCTACCTTAGTCACCTCTTTTG(Ndel) \\
AgR4 & ORF amplification & $(\text { GA })_{3}$ GGATCCTTACACTTTACGACGTCTTAGTAAAAATAC (BamHI) \\
\hline
\end{tabular}

in 30 cycles $\left(94^{\circ} \mathrm{C}, 45 \mathrm{~s} ; 45^{\circ} \mathrm{C}, 45 \mathrm{~s} ; 72^{\circ} \mathrm{C}, 180 \mathrm{~s}\right)$. The final extension step was carried out at $72^{\circ} \mathrm{C}$ for 5 min, and PCR product was purified using the Accuprep $^{\mathrm{TM}}$ PCR purification kit (Bioneer Co., Korea).

\section{Sequence characterization of agrA}

Sequenced gene were analyzed by nucleotide BLAST and Protein BLAST of National Center for Biotechnology Information (NCBI) database. The signal peptide sequence of the $a g r \mathrm{~A}$ was predicted by utilizing a SignalP program (http://www.cbs.dtu.dk/ services/SignalP/), and motif prediction was carried out using a motif-scan prediction program (http:// myhits.isb-sib.ch/cgi-bin/motif_scan). TMHMM Server v. 2.0 was used for the transmembrane site search (http://www.cbs.dtu.dk/services/TMHMM/).

DNassist version 2.2 was used for comparison of other sequences, and Pairwise and multiple alignment of the agarase gene was performed using the ClustalW multiple alignment 1.8 program (Thompson et al., 1994). MEGA 3.1 was used to produce the phylogenetic tree using the neighbor-joining (NJ) method (Kumar et al., 2004).

\section{Cloning of agrA coding sequence into the pET16b expression vector}

Primer set of $\mathrm{AgF} 3$ and $\mathrm{AgR} 4$ were designed with the corresponding restriction enzyme sites of $N d e \mathrm{I}$ and BamHI at the 5'-end and 3'-eend for agrA, respectively (Table 2 ) in order to clone the coding sequence into the pET16b expression vector (Novagen, USA) without including its signal sequence. Amplified PCR product was used as a template for coding sequence amplification. Briefly, a $50 \mu \mathrm{L}$ PCR reaction was set up using 5 units of Herculase DNA polymerase, $5 \mu \mathrm{L}$ of $10 \mathrm{x}$ Herculase buffer, $6 \mu \mathrm{L}$ of $2.5 \mathrm{mM}$ dNTP, $500 \mathrm{ng}$ of template (amplified agrA) and 20 pmol of each primer.

After initial incubation at $94^{\circ} \mathrm{C}$ for $5 \mathrm{~min}, 30$ cycles were carried out $\left(94^{\circ} \mathrm{C}, 30 \mathrm{~s} ; 50^{\circ} \mathrm{C}, 30 \mathrm{~s} ; 72^{\circ} \mathrm{C}\right.$, $180 \mathrm{~s}$ ), followed by a final extension at $72{ }^{\circ} \mathrm{C}$ for 5 min. PCR products were analyzed on a $1 \%$ agarose gel and ethidium bromide staining. The PCR product was purified from the gel with the Accuprep ${ }^{\mathrm{TM}}$ gel purification kit (Bioneer Co., Korea) and digested with the respective restriction enzymes. The expression vector, $\mathrm{pET} 16 \mathrm{~b}$ was also digested with the same restriction enzymes as the PCR product and dephosphorylated with calf intestine phosphatase according to the vendor's protocol. The vector and the PCR product were purified on a $1 \%$ agarose gel using the Qiaex-II gel purification kit (QIAGEN Inc., USA). The ligation was carried out at $20^{\circ} \mathrm{C}$ for $2 \mathrm{~h}$ using a ligation mix (TaKaRa, Japan). The ligated product was transformed into E. coli DH5a cells, and correct recombinants (confirmed by restriction enzyme digestion and sequencing) were transformed into competent cells of $E$. coli BL21.

\section{Overexpression and purification of recombinant AgrA}

E. coli $\mathrm{BL} 21(\mathrm{DE} 3)$ cells carrying the agarase gene (pET-16b-agrA) were overexpressed in the presence of isopropyl- $\beta$-thiogalactopyranoside (IP-TG). Briefly, $5 \mathrm{~mL}$ of an E. coli BL21(DE3) starter culture was inoculated into $100 \mathrm{~mL}$ Luria broth with $100 \mu \mathrm{L}$ ampicillin $(100 \mathrm{mg} / \mathrm{mL})$. The culture was incubated at $37^{\circ} \mathrm{C}$ while shaken at $200 \mathrm{rpm}$ until the cell count reached 0.5 at $600 \mathrm{~nm}$ optical density. The culture was shifted to $12^{\circ} \mathrm{C}$ for $30 \mathrm{~min}$ and induced by IPTG at $1 \mathrm{mM}$ final concentration. After $24 \mathrm{~h}$ of induction, the cells were cooled on ice for $30 \mathrm{~min}$, and harvested by centrifugation at $4,000 \times \mathrm{g}$ for $20 \mathrm{~min}$ at $4^{\circ} \mathrm{C}$, followed by removal of the supernatant. Then cells were resuspended in $5 \mathrm{~mL}$ ice cold $1 \mathrm{x}$ binding buffer (0.5 M NaCl, $20 \mathrm{mM}$ Tris $\mathrm{HCl}, 5 \mathrm{mM}$ imidazole, $\mathrm{pH}$ 7.9) and frozen at $-20^{\circ} \mathrm{C}$ overnight. After thawing on ice, the bacterial cells were sonicated six times in short pulses of $10 \mathrm{~s}$. The supernatant was taken as a crude enzyme after centrifugation at $9,000 \times \mathrm{g}$ for 30 $\min$ at $4^{\circ} \mathrm{C}$. Then, the recombinant AgrA fusion protein was purified using the His Bind Purification Kit (Novagen, USA). In the final purification step, bound fusion protein was eluted with 6 volumes of $1 \mathrm{x}$ elute buffer $(1 \mathrm{M}$ imidazole, $0.5 \mathrm{M} \mathrm{NaCl}, 20 \mathrm{mM}$ Tris-HCl, $\mathrm{pH}$ 7.9). Elutes were collected in $500 \mu \mathrm{L}$ fractions and respective elutes were run on SDSPAGE according to the standard procedure for 
discontinuous SDS-PAGE. Gels were stained using $0.05 \%$ Coomassie Blue R-250, followed by a standard destaining procedure. The concentrations of purified proteins were determined by the method of Bradford using bovine serum albumin (BSA) as the standard (Bradford, M.M. 1976).

\section{Biochemical characterization of recombinant AgrA}

Agarase activity in the recombinant purified protein was determined using the modified method of Ohta et al., 2004a, by measuring the amount of reducing sugars released during incubation with $1 \%$ food grade agar, $1 \%$ agarose and 1\% carrageenan separately as agarase substrates. A suitably diluted enzyme solution was added to different substrates in acetate buffer ( $\mathrm{pH} 5.5)$ supplemented with $2 \mathrm{mM}$ $\mathrm{MgSO}_{4}$, and the mixture was incubated at $65^{\circ} \mathrm{C}$ for $30 \mathrm{~min}$. Activity was expressed as the initial rate of agar hydrolysis by measuring the release of reducing ends using the 3,5-dinitrosalicylic acid (DNS) procedure with D-galactose as the standard. One unit of the enzyme activity was defined as the amount of protein that produced $1 \mu \mathrm{mol}$ of reducing sugar as Dgalactose per min under the conditions of the assay.

Optimum temperature of AgrA was determined by monitoring the relative enzymatic activity at temperatures ranging from $40-70^{\circ} \mathrm{C}$ with $5^{\circ} \mathrm{C}$ in-tervals at $\mathrm{pH}$ 7.0. Optimum $\mathrm{pH}$ of AgrA was tested from $\mathrm{pH}$ 4.5-9.0 with pH 0.5 intervals at $45^{\circ} \mathrm{C}$. Acetate buffer and phosphate buffer were used for $\mathrm{pH}$ 4.5-6.0 and $\mathrm{pH}$ 6.5-9.0, respectively. The thermo-stability of purified recombinant AgrA was evaluated by measuring the residual activity of the enzyme after incubation at the temperatures between $40-65^{\circ} \mathrm{C}$ for 30,60 and $120 \mathrm{~min}$. Effects of various metal ion salts and chelators on purified recombinant AgrA activity were tested by determining the activity in the presence of $2 \mathrm{mM}$ of various ions or chelators $\left(\mathrm{CaCl}_{2}\right.$, $\mathrm{CuSO}_{4}, \mathrm{FeSO}_{4}, \mathrm{KCl}, \mathrm{MgSO}_{4}, \mathrm{MnCl}_{2}, \mathrm{NaCl}$ and EDTA) in a final concentration and incubated at $45^{\circ} \mathrm{C}$ for $30 \mathrm{~min}$. Control was the assay mixture without adding metal ion salts or chelators. In each experiment, $1 \%$ agar solution and purified agarase were mixed and incubated under the conditions of the assay. Agarase activity was determined by the DNS method.

\section{Identification of AgrA hydrolyzed agar products}

Thin layer chromatography (TLC) was used to identify the hydrolysis products of agar and neoagarooligosaccharides. Neoagarohexanitol (NA6) was purchased from Sigma (USA) and neoagarotetraose (NA4) and neoagarobiose (NA2) (NA4+NA2) were prepared by digestion of neoagarohexanitol using commercial $\beta$-agarase (New England Biolab, USA). D- $(+)$-galactose was purchased from Sigma (USA), and all above mentioned oligosaccharides used as standards. Moreover, food grade agar and NA6 were used as substrates for the reactions. The reaction of purified agarase and agar was carried out in $200 \mu \mathrm{L}$ reactions containing $20 \mu \mathrm{L}$ of purified agarase and $180 \mu \mathrm{L}$ of $1 \%$ agar at $45^{\circ} \mathrm{C}$ for 30,60 , and $120 \mathrm{~min}$. NA6 substrate was reacted separately with $20 \mu \mathrm{L}$ of purified agarase at $45^{\circ} \mathrm{C}$ for $120 \mathrm{~min}$. Subsequently, the reaction mixtures were applied to a silica gel 60 TLC plate (Merck, Germany). The TLC plates were developed using a solvent system consist of n-butanol: acetic acid: water $(2: 1: 1, \quad \mathrm{v} / \mathrm{v})$. The resultant oligosaccharide spots after hydrolysis of substrates were visualized by spraying $10 \% \mathrm{H}_{2} \mathrm{SO}_{4}$ to the plate and heating on a hot plate.

\section{Preparation of neoagaro-oligosaccharides}

One gram of agar was dissolved in $100 \mathrm{~mL}$ of triple-distilled water by boiling to make $1 \%$ agar solution. Purified AgrA was mixed into 1\% agar solution and the reaction was performed at $45^{\circ} \mathrm{C}$ for $24 \mathrm{~h}$. Degradation pattern of the products (neo-agarooligosaccharide) was tested using TLC to confirm the hydrolysis of agar. Finally, samples were dried in a freeze dryer and used to check for antioxidant activity in vitro.

\section{Antioxidant activity}

Antioxidant activity of neoagaro-oligosaccharides was determined by examining the results of the DPPH radical scavenging assay. A $100 \mu \mathrm{L}$ aliquot of $0.01,0.1$ and $1 \mathrm{mg} / \mathrm{mL}$ neoagaro-oligosaccharides solution (NA2+NA4) was added into $100 \mu \mathrm{L}$ of $\mathrm{DPPH}$, and incubated at $25^{\circ} \mathrm{C}$ for $60 \mathrm{~min}$ in darkness. A concentration of $0.15 \mathrm{mM}$ DPPH in ethanol was used as the colorimetric reagent, and absorbance was measured at $492 \mathrm{~nm}$ using a microplate reader ELISA.

\section{Nucleotide sequence accession number}

Agra sequence data was submitted to the NCBI database under accession number FJ624295.

\section{Results}

Screening and identification of Agarivorans sp.

Initially, bacteria that showed agar-degrading ability were identified by a clearing zone formed on agar plates. Based on these results, different agarase- 
ATGAAGATTAAATTITTATCTGCAGCAATCGCTGCAAGCTTAGCATTGCCATTAAGTGCTGCTACCTTAGTCACCTCTITTGAGGAAGCG 90

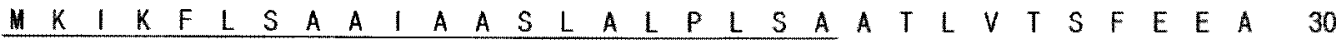
GACTACAGCAGCTCTGAAAACAATACTGAATTCTTGGAAGTGTCTGGAGATGCCACTTCTGAAGTTTCAACTGAACAAGCTACCGATGGT 180 D Y S S S E N N T E F L E V S G D A T S E V S T E O A T T D G AATCAATCCATTAAAGGGTCTTTTGACGGGGCTTTCAAACCAATGGTTGTTTGGAACTGGGGAAGTTGGAACTGGGGCGCTGAAGATGTG 270 $N$ Q $S$ I K A S S F D A A F K P M V V W N W G S W N W G A E D $V$ V 90 ATGTCAGTAGATGTTGTTAACCCTAACGACACTGACGTCACCTITGCTATTAAGCTAATTGATAGTGATATTCTTCCTGATTGGGTAGAT 360 M S V D V V V N P N GAGTCTCAAACCTCATTGGACTACTTTACGGTTTCAGCTAATACCACGCAGACCTITAGCTTTAACTTAAATGGCGGCAACGAGTTCCAA 450

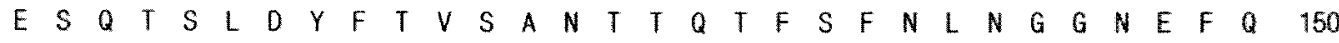
ACTCATGGCGAAAACTITAGTAAAGATAAAGTTATCGGTGTGCAGTTCATGCTCTCTGAAAACGATCCTCAAGTGTTGTACTTIGACAAC 540 T H G E N F S K $D$ D K V I G V Q ATTATGGTTGATGGCGAAACAGTCACTCCGCCACCAAGTGATGGTGCAGTGAATACACAAACCGCGCCTGTAGCCACCTTAGCGCAAATC 630

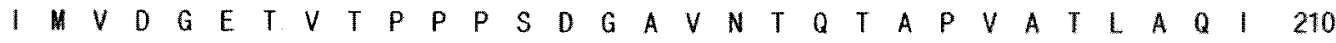
GAAGACTTIGAAACCATTCCAGATTACTTACGACCTGATGGTGGGGTAAACGTTTCAACTACTACTGAGATTGTGACTAAAGGCGCTGCA 720

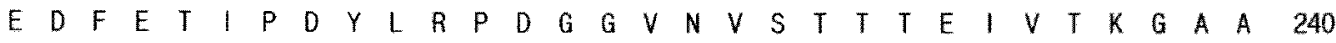
GCAATGGCTGCCGAGTTTACTGCAGGTTGGAACGGTTTAGTGTTTGCAGGTACTTGGAATTGGGCTGAACTAGGTGAACACACCGCAGTT 810 A M A A E F T A G W N G L V F A G T W N W A E L G E H T A V 270 GCCGTTGACGTTTCAAATACTAGCGATAGCAATATCTGGTTGTACTCACGTATCGAAGATGTAAATAGCCAAGgCGAAACAGCGACTCGC 900

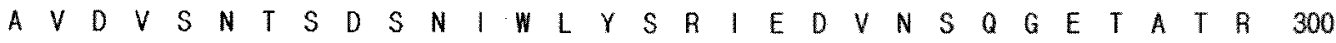
GGCGTATTGGTTAAAGCTGGCGAATCGAAAACCATCTACACCAGCTTAAATGACAACCCTTCATTGCTIACTCAAGATGAGGGCGTGTCA 990

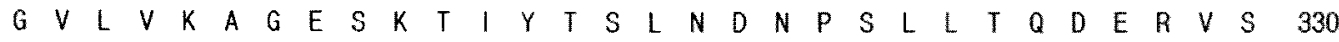
GCTITAGGTITACGTGATATTCCAGCTGACCCAATGAGCGCTCAAAATGGCTGGGGTGATTTTGTTGCTTTAGACAAATCTCAAATTACC 1080

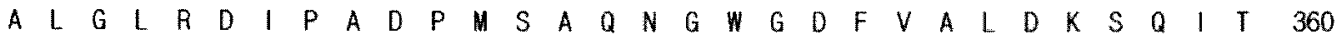
GCTATTCGTTACTTCATTGGGGAATTAGCCAGCGGTGAGACTAGCCAAACACTTGTGTTTGATAACATGCGTGTGATTAAAGACCTTAAC 1170 A I R Y F I G E L A S G E T S O T L V F D N M R V I K D L N 390 CACGAATCAGCCTATGCAGAAATGACTGATGCTATGGGGCAAAACAACTTAGTCACTTATGCAGGTAAAGTTGCCAGGAAAGAAGAGITA 1260

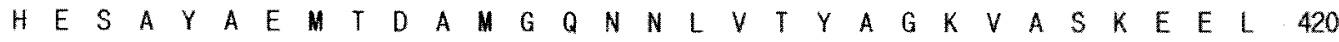
GCTAAGTTAAGTGATCCGGAAATGGCIGTTTTGGGTGAGTTAACCAATCGCAATATGTACGGTGGTAACCCAGATTCGTCGCCAACTACA 1350

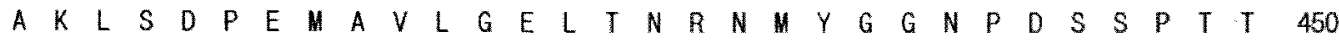
GACTGTGTGCTCGCTACGCCTGCCTCGTTTAACGCTTGTAAAGACGCTGATGGTAACTGGCAATTGGTAGACCCTGCTGGTAATGCGTTC 1440 D C C V V L A A T P A TTCTCAACGGGTGTTGATAACATTCGTTTGCAAGATACTTACACCATGACCGGCGTGTCGAGTGACGCCGAATCTGAGTCTGCACTTCGC 1530

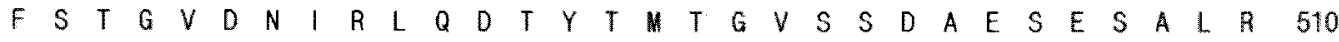
CAGTCAATGTTTACAGAAATTCCAAGTGATTATGTAAATGAAAACTATGGCCCTGTGCATAGTGGACCTGTTTCTCAAGGCCAAGCTGTA 1620 Q S $M$ F T E I P S D Y V N E N Y G P V H S G P V S Q G Q A A V 540 AGTITITAGGCTAATAACTTAATTACCCGCCACGCTAGCGAAGACGTATGGCGAGACATTACTGTTAAGCGCATGAAAGACTGGGGCTI 1710

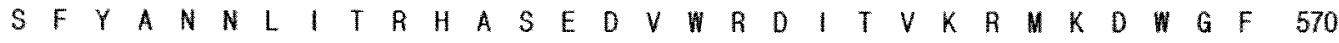
AACACCTTAGGTAACTGGACCGATCCAGCGTTGTATGCAAACGGTGACGTTCCTTACGTGGCAAATGGTTGGTCAACCTCTGGTGCCGAT 1800

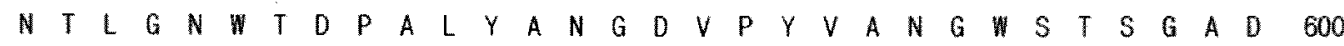
CGTCITCCCGITAAACAAATTGGCAGCGGCTACTGGGGACCACTTCCTGATCCGTGGGATGCTAACTTTGCTACCAAIGCCGCCACAATG 1890

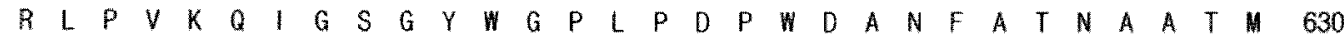
GCTGCAGAGATCAAAGCTCAGGTTGAAGGCAACGAAGAGTACTTAGTGGGTATTTTTGTTGATAACGAAATGAGCTGGGGCAATGTCACT 1980 A A E I K A Q V E G N E E Y L V G I F V D N E M S W G N V T 660 GATGTTGAAGGCTCTCGTTATGCGCAAACGCTAGCAGTGITCAATACCGACGGCACTGATGCAACAACTAGCCCTGCTAAAAATAGCTIT 2070

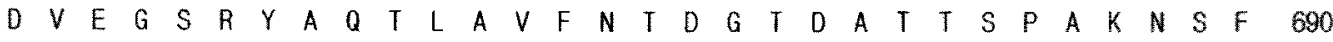

Fig. 1. Nucleotide and deduced amino acid sequences of agrA of Agarivorans sp. AG17. Predicted signal peptide sequence is underlined and stop (TAA) codon is highlighted with an asterisk (*). C-terminal transmembrane domain $\left(\mathrm{G}^{968-} \mathrm{L}^{990}\right.$ aa) is indicated by the double underline. 


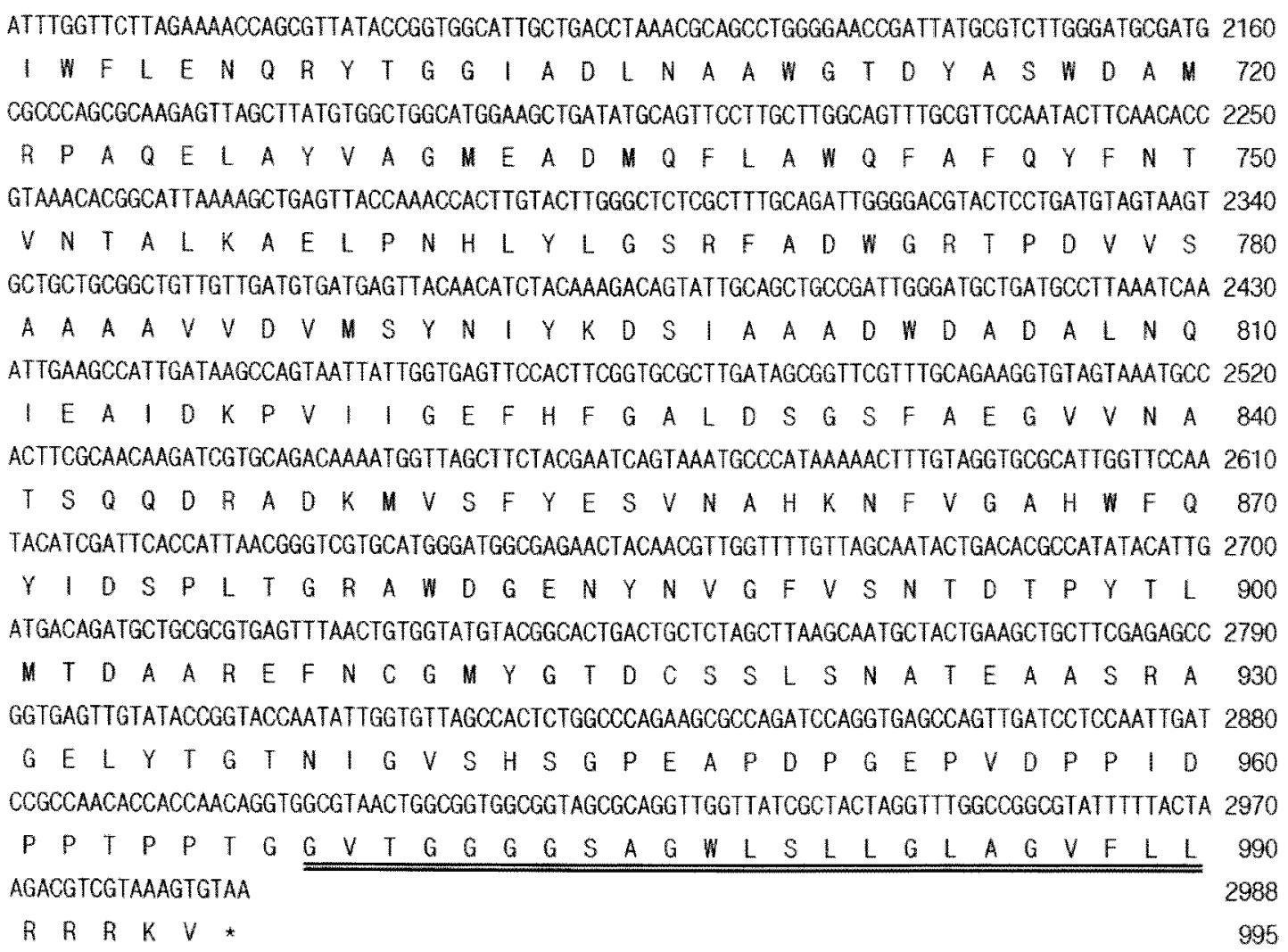

Fig. 1. Continued.

producing bacteria strains were isolated from the samples collected from the Jeju coastal environment. Of the tested bacteria isolated and screened from the red seaweed on SWT, SWY and marine agar, a particular bacteria was identified as Agarivorans sp. according to $16 \mathrm{~S}$ rDNA sequence analysis. NCBI Blast $\mathrm{N}$ results showed that the identified bacterial strain has $99 \%$ identity to Agarivorans sp. JAMBA11 and $A$. albus. We named the identified bacteria strain as Agarivorans sp. AG17.

\section{Cloning and sequence characterization of agr $\mathrm{A}$}

agrA was identified from Agarivorans sp. AG17 after PCR amplification using specific primers as described in Materials and Methods. Nucleotide and amino acid sequence of the Agarivorans sp. AG17 agarase is shown in Fig. 1. It has a 2,985 bp ORF, encoding 995 amino acids. The theoretical molecular mass of agrA putative protein and mature protein was 107 and $105 \mathrm{kDa}$, respectively, with an isoelectric point of $(\mathrm{p} l)$ of 4.1. The $\mathrm{N}$-terminal signal peptide (20 aa) and the C-terminal helical trans-membrane sequence were located at the region of amino acids 120 and 968-990 in $\operatorname{agr} \mathrm{A}$, respectively. ClustalW pairwise identity results revealed that agr A has the highest nucleotide (98.6\%) and amino acid (99.7\%) sequence identity to a $\beta$-agarase sequence of Agarivorans sp. JAMB-A11 (agaA11) (Accession number $\mathrm{AB} 178483$ ), which belongs to the GHF-50. In addition, the protein showed $99.5 \%, 99.2 \%, 99.0 \%$ and 98.2\% amino acid identity for Agarivorans sp. QM38 agarase (agaD01) (Accession number EF051475), $\beta$-agarase (AgaA) from Vibrio sp. JT0107 (Accession number BAA-03541), Agarivorans sp. JA- $\beta$-agarase (Accession number EF100136) and Vibrio sp. PO-303 agaB gene (Accession number $\mathrm{AB} 232056$ ), which belongs to GHF-50, respectively.

\section{Phylogenetic analysis of the agrA}

To determine the relationship between isolated agr A with known agarase sequences, a phylogenetic tree was constructed based on their primary amino acid sequences using the Neighbor-joining method in MEGA3.1 (Fig. 2). Phylogenetic analysis results showed that agarase amino acid sequences, which belong to the GHFs 16,50 and 86 positioned in separate clusters and within that, clusters were subdivided into many sub-clusters. Moreover, agr A was related to a member of GHF-50 and formed a monophyletic clade with other agarase sequences in 


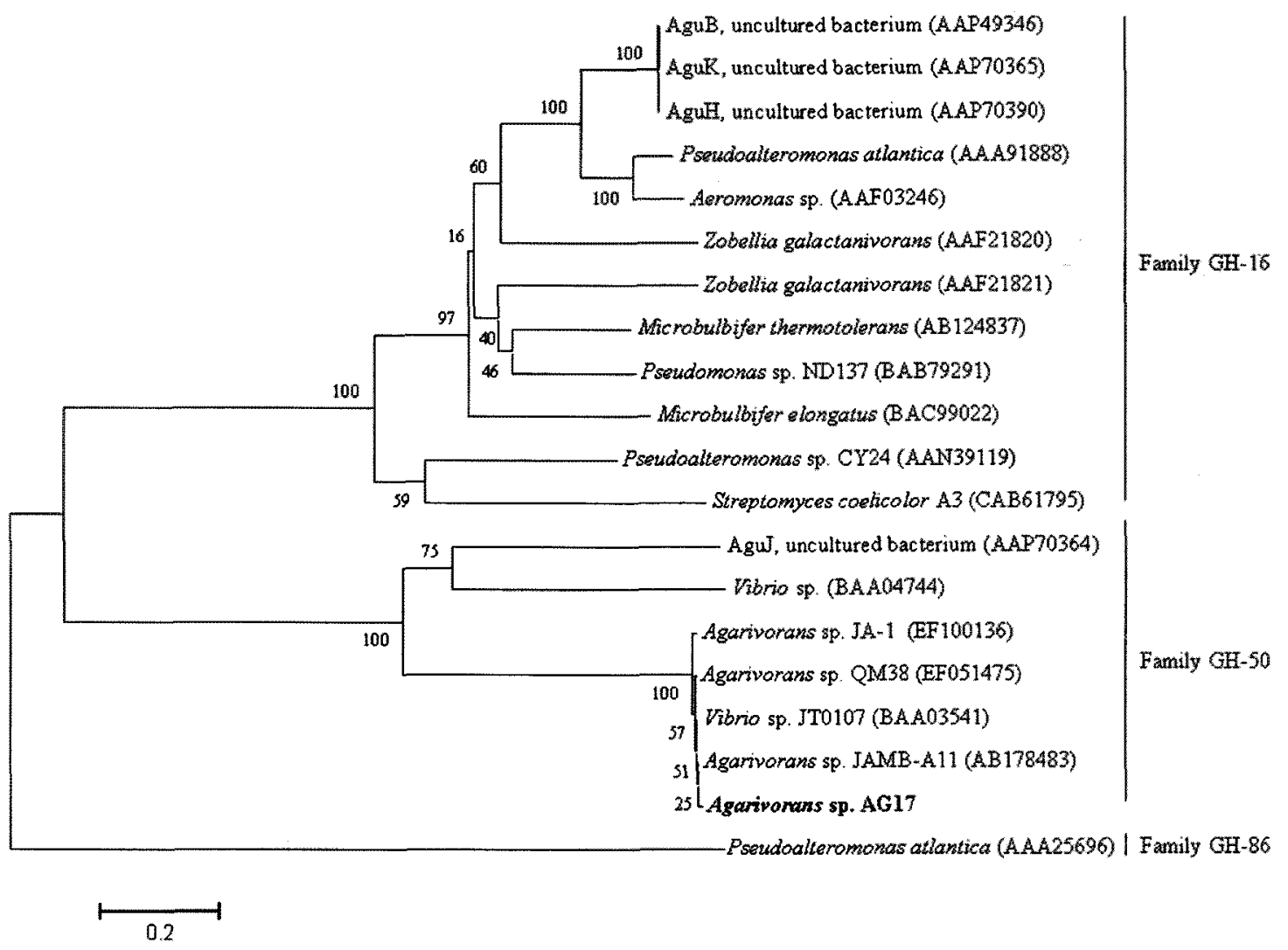

Fig. 2. Phylogenetic analysis of agrA with known agarases based on amino acid sequence. Phylogenetic analysis was done by NJ method using MEGA3.1 based on sequence alignment using ClustalW (1.81). Numbers indicate the bootstrap confidence values of 1000 replicates. The accession numbers of the selected agarase sequences are as follows: AB178483, agarase (Agarivorans sp. JAMB-A11); EF051475, QM38 agarase (Agarivorans sp. QM38); EF100136, $\beta$-agarase (Agarivorans sp. JA-1); AAA25696, $\beta$-agarase precursor (Pseudoalteromonas atlantica); AAP49346, AguB; AAP70390, AguH; AAP70365, AguK from uncultured bacterium; AAA91888, $\beta$-agarase I (Pseudoalteromonas atlantica); AAF03246, $\beta$-agarase (Aeromonas sp.); AB124837, agarase (Microbulbifer thermotolerans); BAC99022, agarase (Microbulbifer elongatus); BAB79291, agarase, (Pseudomonas sp. ND137; AAF21821, $\beta$-agarase B precursor (Zobellia galactanivorans); AAF21820, $\beta$-agarase A precursor (Zobellia galactanivorans); AAN39119, extracellular agarase precursor, (Pseudoalteromonas sp. CY24); CAB61795, extracellular agarase precursor (Streptomyces coelicolor A3); AAP70364, AguJ (uncultured bacterium); BAA04744, $\beta$-agarase (Vibrio sp.); BAA03541, $\beta$-agarase (Vibrio sp. JT0107).

the GHF-50.

\section{Expression and purification of recombinant AgrA}

agrA mature sequence was cloned into the $\mathrm{pET} 16 \mathrm{~b}$ expression vector that fused with a his tag at the $\mathrm{N}$ terminal. The recombinant AgrA was overexpressed in E. coli BL21 (DE3) cells by IPTG induction and purified as a his-tag fusion protein. The $12 \%$ SDSPAGE results of different steps in the recombinant AgrA purification is shown in Fig. 3. It was very clear that AgrA was highly induced (lane 2) compare to un-induced cells (lane 1). Then, the recombinant AgrA fusion protein was purified from soluble crude protein extract by a $\mathrm{Ni}^{2+}$ binding column (lane 4 ). The size of the purified protein was identified as $108 \mathrm{kDa}$, which is identical to the mature protein size together with the his-tag protein.

\section{Biochemical characterization of recombinant AgrA}

Specific activities were determined using agar, agarose and carrageenan as substrates. Purified recombinant AgrA showed 158.8 and 155.3 unit $/ \mathrm{mg}$ towards agar and agarose, respectively. However, no agarase activity was detected towards carrageenan. The effect of temperature on the activity of AgrA is shown in Fig. 4. Optimum temperature of purified recombinant AgrA activity was determined at 

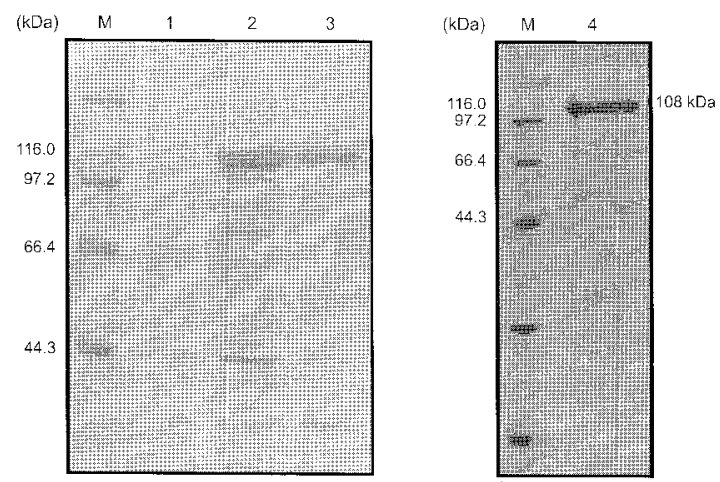

Fig. 3. SDS-PAGE of the recombinant protein AgrA. Protein samples were separated on 12\% SDS-PAGE and stained with Coomassie brilliant blue. $\mathrm{M}$ : molecular mass marker (BioRad, USA). Lane 1: total cellular extract from E. coli BL21 (DE3) before induction; lane 2: total cellular soluble extract after induction; lane 3: total cellular insoluble extract after induction; lane 4: purified recombinant AgrA.

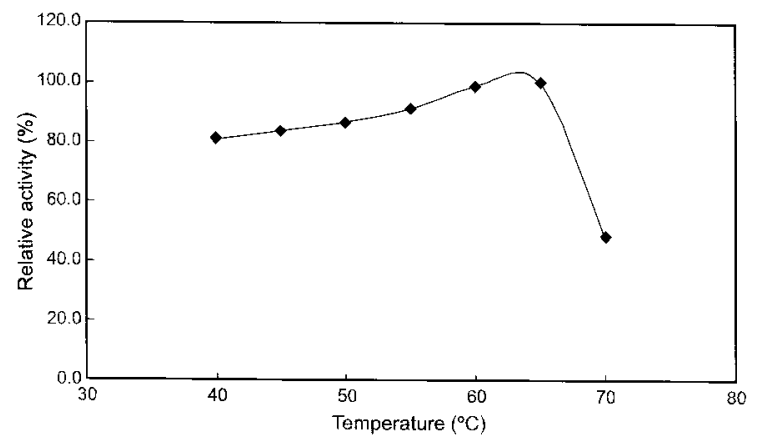

Fig. 4. Effect of temperature on the activity of purified recombinant AgrA. Effect of temperature on enzyme activity was determined under standard assay conditions as described in Materials and Methods, at temperatures ranging between $40-70^{\circ} \mathrm{C}$.

different temperatures ranging from $40-70^{\circ} \mathrm{C}$ in $5^{\circ} \mathrm{C}$ intervals. Within the range of $\mathrm{t}$ he tested temperatures, the activity of the enzyme increased up to $65^{\circ} \mathrm{C}$, and this was shown as the optimal temperature for the enzyme. Once the temperature rose above $65^{\circ} \mathrm{C}$, the activity of the enzyme decreased drastically. However, relative activity was retained approximately $50 \%$ at the temperature of $70^{\circ} \mathrm{C}$.

Effect of $\mathrm{pH}$ on the purified AgrA is shown in Fig. 5. Higher activity was obtained in the range of $\mathrm{pH}$ from 4.5-8.5 and in all this range, more than $90 \%$ of relative activity was retained. However, optimum $\mathrm{pH}$ was obtained at $\mathrm{pH} 5.5$ in acetate buffer.

Fig. 6 shows the thermostability of AgrA. Six different temperatures $\left(40,45,50,55,60\right.$ and $\left.65^{\circ} \mathrm{C}\right)$ were used to determine the thermostability of AgrA

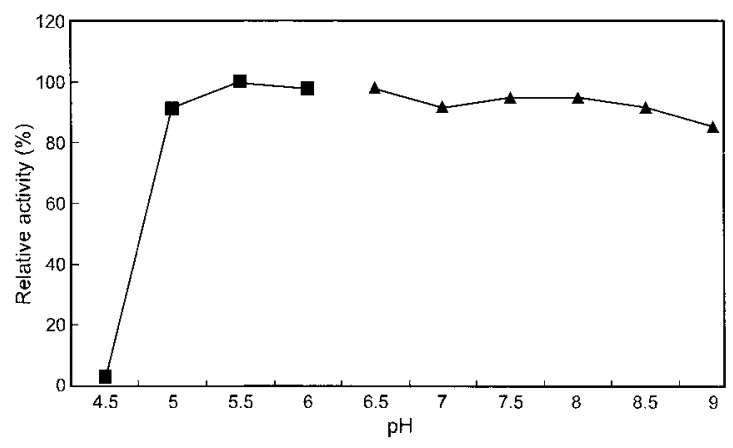

Fig. 5. Effect of $\mathrm{pH}$ on the activity of purified recombinant AgrA. Optimum pH for AgrA activity was tested from $\mathrm{pH} 4.5-9.0$ at $\mathrm{pH} 0.5$ intervals at $45^{\circ} \mathrm{C}$ under standard assay conditions as described in Materials and Methods using acetate $(\mathrm{pH} 4.5-6.0)$ and phosphate buffer ( $\mathrm{pH}$ 6.5-9.0).

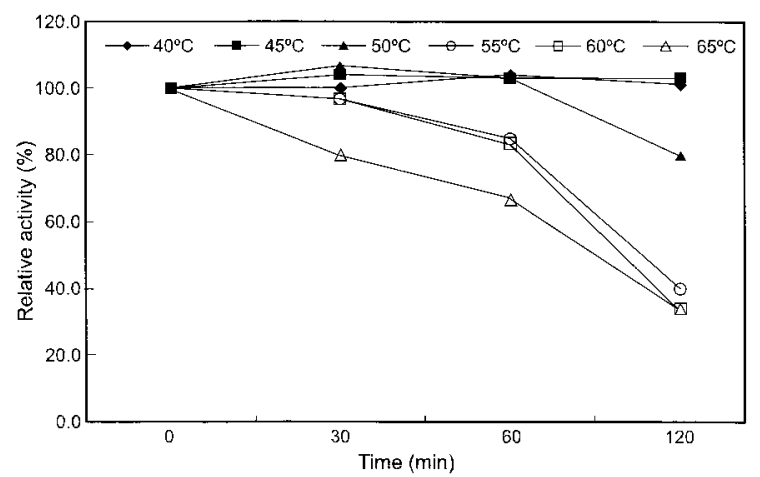

Fig. 6. Effect of thermostability on purified recombinant AgrA at different temperatures for different time points. Thermostability was determined by measurement of residual activity under standard assay conditions as described in Materials and Methods at temperatures between $40-65^{\circ} \mathrm{C}$ for 30,60 and 120 min.

with respect to different incubation time points at 30 , 60 and $120 \mathrm{~min}$. Enzyme was thermostable (almost $100 \%$ of relative activity) at 40 and $45^{\circ} \mathrm{C}$. Moreover, about $80 \%$ of the relative activity was retained at $50^{\circ} \mathrm{C}$ up to $120 \mathrm{~min}$. Interestingly, AgrA showed $82 \%$ activity after incubation at 55 and $60^{\circ} \mathrm{C}$ for $1 \mathrm{~h}$ and activity was retained about $40 \%$ for $2 \mathrm{~h}$ at $55^{\circ} \mathrm{C}$. Even though the thermostability decreased at 60 and $65^{\circ} \mathrm{C}$ at the time of $120 \mathrm{~min}$ (up to $40 \%$ relative activity), thermostability was retained more than $60 \%$ at 60 min.

Effects of metal ion salts and chelators on activity of purified AgrA is shown in Fig. 7. More than 40\% of the relative activity was inhibited in the protein by $2 \mathrm{mM}$ divalent metal salts such as $\mathrm{CuSO}_{4}$ and $\mathrm{ZnSO}_{4}$, and also by $\mathrm{FeSO}_{4}$ and $\mathrm{MnCl}_{2}$ (by $20 \%$ ). In contrast, $\mathrm{MgSO}_{4}, \mathrm{NaCl}, \mathrm{KCl}$ enhanced the relative activity 
when compared to the control. However, there was no difference observed in relative activity of AgrA, which had $\mathrm{CaCl}_{2}$ and EDTA in the reaction mixtures, when compared to the control samples.

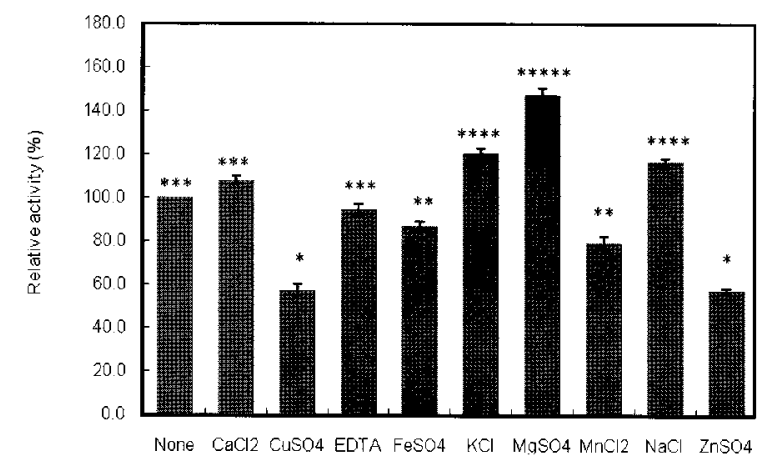

Fig. 7. Effect of metal ions and metal salts on the activity of purified recombinant AgrA. The effect of various metal ion salts and chelators on purified recombinant AgrA activity. Various ions or chelators $\left(\mathrm{CaCl}_{2}, \mathrm{CuSO}_{4}, \mathrm{FeSO}_{4}, \mathrm{KCl}, \mathrm{MgSO}_{4}, \mathrm{MnCl}_{2}, \mathrm{NaCl}\right.$ and EDTA) at a final concentration of $2 \mathrm{mM}$ were included in the reaction buffer to test the activity of AgrA at $45^{\circ} \mathrm{C}$ for $30 \mathrm{~min}$. The data presented are the average of three replicates. Means with the same number of stars are not significantly different at $P<0.05$, based on ANOVA. Error bars represent $\pm \mathrm{SD}$.

\section{Identification of hydrolysis products of the recom- binant AgrA on TLC}

Hydrolysis patterns of the purified AgrA against food grade agar and neoagarohexanitol (NA6) are shown in Fig. 8. When the AgrA is incubated with food grade agar, NA4 and NA2 were detected on TLC plate at early stage of the reaction. The amount of NA2 production was increased in a timedependent manner. A higher amount of NA2 was observed at 60 and $120 \mathrm{~min}$, compared to $30 \mathrm{~min}$ of hydrolysis. Furthermore, when the AgrA was incubated with NA6 at $120 \mathrm{~min}$, two reaction products, NA4 and NA2 were observed on TLC.

\section{Discussion}

In the present study, the isolation, cloning, expression and characterization of a thermostable agr A from Agarivorans sp. AG17, isolated from red seaweed G. filicina at Jeju coastal area was described. Reported selection plates, which have been used for screening of agarase producing bacteria are rich medium containing agar Lee et al., 2006; Vera et al., 1998). However, in this study, SW agar plates were used, which contained only agar as a sole carbon source that allows for the growth of different kind of

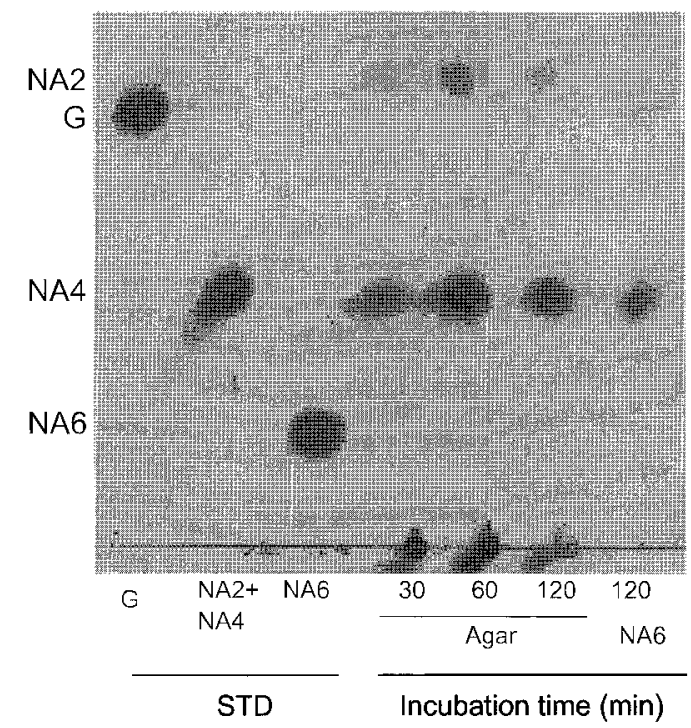

Fig. 8. TLC of hydrolysis products of the purified AgrA enzyme on food grade agar and neoagarooligosaccharides. The assay of purified AgrA and agar were performed in $200 \mu \mathrm{L}$ reactions containing $20 \mu \mathrm{L}$ of purified agarase and $180 \mu \mathrm{L}$ of $1 \%$ agar at $45^{\circ} \mathrm{C}$ for 30,60 , and 120 min. NA6 substrate was incubated with $20 \mu \mathrm{L}$ of purified AgrA separately at $45^{\circ} \mathrm{C}$ for $120 \mathrm{~min}$. Neoagarohexaitol (NA6), neoagarotetraose (NA4), neoagarobiose (NA2) and D- $(+)$-galactose $(\mathrm{G})$ were used as standards (STD).

bacteria for the first step of screening of agaraseproducing bacteria. An agarase-producing bacteria strain was identified by $16 \mathrm{~S}$ rDNA sequencing and it showed the highest identity (99\%) to Agarivorans sp. JAMB-A11 and A. albus. Therefore, the identified bacteria strain was named as Agarivorans sp. AG17 and was selected for isolation of the agarase encoding gene agrA. At present, many agarase-producing bacteria have been identified. However, there are a few bacteria that belong to genus Agarivorans, which produce agarases that have been reported such as Agarivorans sp. JAMB-A11 (Ohta et al., 2005), JA-1 (Lee et al., 2006), QM35 (Du et al., 2007) and $A$. Albus YKW-34 (Fu et al., 2008b). In some of these strains, the primary structure of the agarase gene has been characterized their biochemical properties of the enzyme were also characterized.

It has been reported that the molecular masses of reported Agarivorans sp. agarases ranged from 105$107 \mathrm{kDa}$ except for the agarase AgaA34 (50 kDa) purified from A. Albus YKW-34 (Fu et al., 2008b). The agrA also showed a $107 \mathrm{kDa}$ theoretical molecular mass with mature protein of $105 \mathrm{kDa}$. The first 20 residues of amino acids in $a g r A$ constitute a hydrophobic region $(70 \%)$ that function as a signal 
peptide for secretion of the agarase. When the agrA amino acid sequence was compared with other agarase sequences for their consensus signature motifs, no characteristic motifs and carbohydrate binding modules were found, suggesting that it does not belong to GHF-16 or 86 . Phylogenetic analysis results of this study shows that agrA is deviated from the GHF16 clade and positioned separately in a separate monophyletic clade, suggesting that agr A belongs to the GHF-50. Agarase enzymes share a common ancestor (Allouch et al., 2003) and data indicate that agrA has diverged from the primary ancestral sequence. However, agarases feature common catalytic residues in their sequence. The glutamic and aspartic acid are the highly conserved active site residues, which responsible for catalytic activity in GHF (Ma et al., 2007). There were 7.8 and $5.6 \%$ aspartic and glutamic acids present in the agr A amino acid sequence, respectively, and some of those may responsible for the catalytic activity of the protein. Pseudoalteromonas atlantica T6c AgrA (AAA25696) which belongs to GHF-86 showed low amino acid identity (8\%) to agrA. However, amino acid sequence from 202-354 of $P$. atlantica T6c and $301-480$ of agrA showed 50\% of conserved catalytic residues within that range. Conserved catalytic residues may differently position among agarases in different GHFs due to the diversification of their sequences. This confirms the heterogeneity of the amino acid sequences, catalytic properties and substrate specificities in agarases.

AgrA hydrolyzes agar to give neoagarohexaose, neoagarotetraose and agarobiose as the main products. After 30, 60 and $120 \mathrm{~min}$ incubation of $1 \%$ agar with AgrA, the main hydrolysis products observed were NA4 and NA2. This suggests that the purified recombinant enzyme is an endo-type $\beta$-agarase that catalyzed the hydrolysis of $\beta$-1,4-linkages in agar and belongs to GHF-50. Similar to this study, it has been reported that AgaA of GHF-50 from Vibrio sp. strain JT0107 degrades agarose as well as agarose oligosaccharides containing at least four sugars to yield neoagarobiose (Sugano et al., 1993a). In contrast, AgrA from $P$. atlantica T6c in GHF-86 degrades agarose into a more polymerized compound than hexamers to yield neoagarohexaose (Ohta et al., 2004a). Some agarases of GHF-16 degrade agarose and agarose oligosaccharides containing six sugars to yield neoagarotetraose (Schroeder et al., 2003; Allouch et al., 2003).

The known $\beta$-agarases are grouped into the GHF16,50 and 86 , and GHF-16 is the most abundant among them. Although the sequence-based GHFs contain enzymes of similar folding and identical molecular mechanisms, there are varying substrate specificities within the same families. Therefore, different sub-strates such as agar, agarose and carrageenan were selected to identify the substrate specificity of AgrA and it was confirmed that the recombinant enzyme selectively hydrolyzed agarderivative products.

Generally most of the $\beta$-agarases show a temperature optimum around $40^{\circ} \mathrm{C}$ (higher than the gelling temperature of agarose) and an optimum $\mathrm{pH}$ around neutral to mild alkaline (Zhang and Sun 2007; Lee et al., 2006). The high thermostability and activity at temperatures higher than the gelling temperatures of agar is useful for industrial oligosaccharide production from marine agar or algae (Ohta et al., 2004c) which could degrade its cell wall for extraction of labile substances with many biological activities (Yoshizawa et al., 1995; Araki and Morishita, 1998). Interestingly, the recombinant AgrA showed optimum activity at $65^{\circ} \mathrm{C}$ and $\mathrm{pH} 5.5$. It was reported that the optimum temperature of the enzyme below the gelling temperature $\left(38^{\circ} \mathrm{C}\right)$ of agarase reduces the enzyme action due to compact bundles of gel structure in agarose (Van der Meulen and Harder, 1975). Therefore, we could suggest that the higher optimum temperature at $65^{\circ} \mathrm{C}$ would help to enhance the AgrA activity. So far, the highest thermostability reported for agarases isolated from Agarivorans sps. were between $35-50^{\circ} \mathrm{C}$ (Van der Meulen and Harder, 1975; Kirimura et al., 1999; Suzuki et al., 2003). Interestingly, the thermostability of AgrA was observed at $65^{\circ} \mathrm{C}$, which retained its activity more than $60 \%$ for $60 \mathrm{~min}$, as reported in the present study herein. With agreement to this, the thermostable $\beta$-agarase ( $\mathrm{rAgaA}$ ) from novel marine bacterium JAMB-A94 was stable up to $60^{\circ} \mathrm{C}$, and more than $80 \%$ of the activity was retained at $65^{\circ} \mathrm{C}$ for $15 \mathrm{~min}$ of heating (Ohta et al., 2004c). Nevertheless, AgrA in the present study represents the novel biochemical properties compared to previously reported agarases from Agarivorans sp. Therefore, AgrA could be much more useful in the industries for preparation of oligosaccharides than the reported enzymes due to the unique characteristic features of the enzyme.

In the preliminary AgrA overexpression studies, a higher amount of insoluble protein was detected at higher induction temperatures such as $25^{\circ} \mathrm{C}$ and $37^{\circ} \mathrm{C}$. Therefore, low temperature $\left(12^{\circ} \mathrm{C}\right)$ overexpression was used, and it may be useful to increase the solubility of the protein and reduce the inclusion body formation. Furthermore, it suggests that the 
conditions utilized here favored to produce the correct folding conformation of AgrA to give the thermostable and $\mathrm{pH}$ stable properties of the protein, which would be beneficial for industry. To understand the exact catalysis mechanism of AgrA, the crystal structure of the enzyme needs to be examined in future. Similar to previous reports of the betaagarases, $\mathrm{MgSO}_{4}, \mathrm{NaCl}$ and $\mathrm{KCl}$ positively affected the activity of the recombinant AgrA. The maximal activity (specific activity $167 \mathrm{U} / \mathrm{mg}$ ) of recombinant Agarivorans sp. JA-1 was at $40^{\circ} \mathrm{C}$ and $\mathrm{pH} 8.0$ in the presence of $1 \mathrm{mM} \mathrm{NaCl}$ and $1 \mathrm{mM} \mathrm{CaCl}$ (Lee et al., 2006). As reported herein, the $\mathrm{CaCl}_{2}$ did not show significant effect on the activity of the recombinant AgrA. However, $\mathrm{CaCl}_{2}$ could stabilize the activity of GHF-86 $\beta$-agarase AgaO and enhanced the activity of $\mathrm{AgaB}$ of the Pseudoalteromonas sp. (Ohta et al., 2004a; Ma et al., 2007). Similar results have been reported by Zhang and Sun (Zhang and Sun, 2007) with no measurable effect on the activity of the recombinant $\beta$-agarase AgaV enzyme (isolated from V134, a marine isolate of the Vibrio genus) at concentrations of up to $10 \mathrm{mM} \mathrm{CaCl}_{2}$, and exerted an apparently inhibitory effect at higher concentrations (Zhang and Sun, 2007). This further confirms the high degree of heterogeneity among $\beta$-agarases.

It has been reported that kojic acid and arbutin are natural tyrosinase inhibitors, which have been used for the tyrosinase inhibition and whitening effects. However, the major drawback of using these is their cytotoxicity (Briganti et al., 2003). The whitening effect of neoagaro-oligosaccharides on the B16F10 murine melanoma cell line was studied by Lee et al. (Lee et al., 2006) and a similar whitening effect was observed at $10 \mu \mathrm{g} / \mathrm{mL}$ in the present study. Similar to their study, the AgrA hydrolyzed neoagaro-oligosaccharides were not cytotoxic to B16F10 murine melanoma and normal human fibroblast cells at concentrations $0.1-100 \mu \mathrm{g} / \mathrm{mL}$ (data not shown in the present study, to avoid repetition). Moreover, in this study, neoagaro-oligosaccharides prepared by purified AgrA showed antioxidant activities (50\% at 1.0 $\mathrm{mg} / \mathrm{mL}$ ) by scavenging production of free radicals, however, at a lower level than commercial vitamin $\mathrm{C}$ and $\mathrm{E}(90 \%)$. Several explanations on the in vitro antioxidation mechanism of polysaccharide have been reported (Jimenez-Escrig et al., 2001; Xue et al., 2001). DPPH scavenging activity is widely accepted and an easy-to-use in vitro assay to measure the activity of various antioxidants through a proton donation mechanism (Chen et al., 2005; Hu et al., 2004). Inhibiting the production of lipid peroxidation and inhibiting the production of NO were some of the antioxidant effects of agaro-oligosaccharides (Chen et al., 2005). This confirms that neoagaro-oligosaccharides produced by AgrA are biologically active as reported by Kobayashi et al. (Kobayashi et al., 1997) and Lee et al. (Lee et al., 2006).

In conclusion, an agar-degrading bacteria was isolated from red seaweed, G. filicina samples collected from Jeju Island and was named as Agarivorans sp. AG17 on the basis of $16 \mathrm{~S}$ rDNA sequence analysis. The agrA was cloned and sequenced from Agarivorans sp. AG17. Recombinant enzyme was overexpressed and purified using an $E$. coli bacterial expression system and it showed distinguishable biochemical characteristics compared to reported agarases. TLC analysis revealed that AgrA could degrade agar mainly into neoagarohexaose, neoagarotetraose and neoagarobiose functionally confirming that AgrA is $\beta$-agarase. Together with the biochemical and functional characteristics, purified recombinant AgrA could be used for the production of neoagarohexaose, neoagarotetrose and neoagarobiose from agar. Since generated simple neo-oligosaccharides from complex polysaccharides have whitening and antioxidant activity, the hydrolysis products identified here could be useful for industrial applications. Furthermore, the reaction mechanisms of agar oligosaccharide functional activities need to be studied more in detail in the future.

\section{Acknowledgements}

This research was financially supported by the Ministry of Education, Science Technology (MEST) and Korea Industrial Technology Foundation (KOTEF) through the Human Resource Training Project for Regional Innovation, and by a research grant (PE98472) from Korea Ocean Research \& Development Institute.

\section{References}

Allouch J, Jam M, Helbert W, Barbeyron T, Kloareg B, Henrissat B and Czjzek M. 2003. The three-dimensional structures of two beta agarases. J Biol Chem 278, 47171-47180.

Aoki T, Araki T and Kitamikado M. 1990. Purification and characterization of a novel beta-agarase from Vibrio sp. AP-2. Eur J Biochem 187, 461-465.

Araki C. 1966. Some recent studies on the polysaccharide of agarophytes. In: Proceedings International Seaweed Symposium, Young EG and Maclachan JL, eds. Pergamon, London, 3-17. 
Araki T, Lu Z and Morishita T. 1998. Optimization of parameters for isolation of protoplasts from Gracilaria verrucosa (Rhodophyta). J Mar Biotechnol 6, 193-197.

Bradford MM. 1976. A rapid and sensitive method for the quantification of microgram quantities of protein utilizing the principle of protein-dye binding. Anal Biochem 72, 248-254.

Briganti S, Camera E and Picardo M. 2003. Chemical and instrumental approaches to treat hyperpigmentation. Pigment Cell Res 16, 101-110.

Chen HM, Zheng L and Yan XJ. 2005. The preparation and bioactivity research of agaro-oligosaccharides. Food Technol Biotechnol 43, 29-36.

Du ZJ, Zhao Y, Li MJ, Chi MZ and Wu LF. 2007. Screening and biodiversity analysis of agarolytic bacteria in the Qingdao coast. Periodical Ocean Univ. China 37, 277-282.

Duckworth M and Turvey JR. 1969. The action of a bacterial agarase on agarose, porphyran and alkali treated porphyran. Biochem J 113, 687-692.

Duckworth M and Yaphe W. 1971. Structure of agar. I. Fractionation of complex mixture of polysaccharides. Carbohydr Res 16, 189-197.

Ekborg NA, Taylor LE, Longmire AG, Henrissat BR, Weiner $\mathrm{M}$ and Hutcheson SW. 2006. Genomic and proteomic analyses of the agarolytic system expressed by Saccharophagus degradans 2-40. Appl Environ Microbiol 72, 3396-3405.

Fu W, Han B, Duan D, Liu W and Wang C. 2008a. Purification and characterization of agarases from a marine bacterium Vibrio sp. F-6. J Indust Microbiol Biotechnol 35, 915-922.

$\mathrm{Fu}$ XT, Lin $\mathrm{H}$ and Kim SM. 2008b. Purification and characterization of a novel beta-agarase, AgaA34, from Agarivorans albus YKW-34. Appl Microbiol Biotechnol 78, 265-273.

Groleau D and Yaphe W. 1977. Enzymatic hydrolysis of agar: purification and characterization of beta-neoagarotetraose hydrolase from Pseudomonas atlantica. Can J Microbiol 23, 672-679.

Ha JC, Kim JT, Kim SK, Oh TK, Yu JH and Kong IS. 1997. Beta agarase from Pseudomonas sp. W7: purification of the recombinant enzyme from Escherichia coli and the effects of salt on its activity. Biotechnol Appl Biochem 26, 1-6.

Hassairi I, Ben AR, Nonus M and Gupta BB. 2001. Production and separation of alpha-agarase from Altermonas agarlyticus strain GJ1B. Biores Technol 79, 47-51

Hu FL, Lu RL, Huang B, Ming L. 2004. Free radical scavenging activity of extracts prepared from fresh leaves of selected Chinese medicinal plants.
Fitoterapia 75, 14-23.

Jam M, Flament D, Allouch J, Potin P, Thion L, Kloareg B, Czjzek M, Helbert W, Michel $\mathrm{G}$ and Barbeyron $\mathrm{T}$. 2005. The endo-beta-agarases AgaA and AgaB from the marine bacterium Zobellia galactanivorans: two paralogue enzymes with different molecular organizations and catalytic behaviours. Biochem Journl 385, 703-713.

Jimenez-Escrig A, Jimenez-Jimenez I, Pulido R and SauraCalixto F. 2001. Antioxidant activity of fresh and processed edible seaweeds. J Sci Food Agric 81, 530534.

Kendall K and Cullum J. 1984. Cloning and expression of an extracellular-agarase from Streptomyces coelicolor A3(2) in Streptomyces lividans 66. Gene 29, 315-321.

Kirimura K, Masuda N, Iwasaki Y, Nakagawa H, Kobayashi R and Usami S. 1999. Purification and characterization of a novel beta agarase from an alkalophilic bacterium, Alteromonas sp. E-1. J Biosci Bioeng 87, 436-441.

Kobayashi R, Takisada M, Suzuki T, Kirimura K and Usami S. 1997. Neoagarobiose as a novel moisturizer with whitening effect. Biosci Biotechnol Biochem 61, 162-163.

Kumar S, Tamura K and Nei M. 2004. MEGA3: Integrated software for molecular evolutionary genetics analysis and sequence alignment. Brief Bioinform 5, 150-163.

Lee S, Park J, Yoon S, Kim J and Kong I. 2000. Sequence analysis of a beta-agarase gene (pjaA) from Pseudomonas sp. isolated from marine environment. J Biosci Bioeng 89, 485-488.

Lee DG, Park GT, Kim NY, Lee EJ, Jang MK, Shin YG, Park GS, Kim TM, Lee JW, Lee JH, Kim SJ and Lee SH. 2006. Cloning, expression, and characterization of a glycoside hydrolase family 50 beta-agarase from a marine Agarivorans isolate. Biotechnol Lett 28, 1925-1932.

Ma C, Lu X, Shi C, Shi C, Li J, Gu Y, Ma Y, Chu Y, Han F and Gong Q. 2007. Molecular cloning and characterization of a novel beta-agarase, AgaB, from marine Pseudoalteromonas sp. CY24. J Biol Chem 282, 3747-3754.

Miller GL. 1959. Use of dinitrosalicylic acid reagent for determination of reducing sugar. Anal Chem 31, 426428.

Morrice LM, McLean MW, Williamson FB and Long WF. 1983. Beta-agarases I and II from Pseudomonas atlantica. Purifications and some properties. Eur J Biochem 135, 553-558.

Naganuma T, Coury DA, Poline-Fuller M, Gibor A and Horikoshi K. 1993. Characterization of agarolytic Microscilla isolates and their extracelluar agarases. Sys Appl Microbiol 16, 183-190. 
Ohta Y, Hatada Y, Nogi Y, Li Z, Ito S and Horikoshi K. 2004a. Cloning, expression, and characterization of a glycoside hydrolase family 86 beta agarase from a deep-sea Microbulbifer-like isolate. Appl Microb Biotechnol 66, 266-275.

Ohta Y, Hatada Y, Nogi Y, Miyazaki M, Li Z, Akita M, Hidaka Y, Goda S, Ito S and Horikoshi K. 2004b. Enzymatic properties and nucleotide and amino acid sequences of a thermostable beta-agarase from a novel species of deep-sea Microbulbifer. Appl Microb Biotechnol 64, 505-514.

Ohta Y, Hatada Y, Nogi Y, Miyazaki M, Li Z, Hatada Y, Ito $\mathrm{S}$ and Horikoshi K. 2004c. Enzymatic properties and nucleotide and amino acid sequences of $a$ thermostable beta agarase from the novel marine isolate, JAMB-A94. Biosci Biotechnol Biochem 68, 1073-1081.

Ohta Y, Hatada Y, Ito S and Horikoshi K. 2005. High-level expression of a neoagarobiose-producing beta-agarase gene from Agarivorans sp. JAMB-A11 in Bacillus subtilis and enzymic properties of the recombinant enzyme. Biotechnol Appl Biochem 41, 183-191.

Potin P, Richard C, Rochas C and Kloareg B. 1993. Purification and characterization of the alpha-agarase from Alteromonas agarlyticus (Cataldi) comb. nov., strain GJ1B. Eur J Biochem 214, 599-607.

Ryu SK, Cho SJ, Park SR, Lim WJ, Kim MK, Hong SY, Baed W, Park YW, Kim BK, Kim H and Yun HD. 2001. Cloning of the cel9A gene and characterization of its gene product from marine bacterium Pseudomonas sp. SK38. Appl Microb Biotechnol 57,138-145.

Schroeder DC, Jaffer MA and Coyne VE. 2003. Investigation of the role of a beta (1-4) agarase produced by Pseudoalteromonas gracilis B9 in eliciting disease symptoms in the red alga Gracilaria gracilis. Microbiol 149, 2919-2929.

Sugano Y, Matsumoto T, Kodama H and Noma M. 1993a. Cloning and sequencing of agaA, a unique agarase 0107 gene from a marine bacterium, Vibrio sp. Strain JT0107. Appl Environ Microbiol 59, 3750-3756.

Sugano Y, Terada I, Arita M, Noma M and Matsumoto T. 1993b. Purification and characterization of a new agarase from a marine bacterium, Vibrio sp. strain JT0107. Appl Environ Microbiol 59, 1549-1554.

Suzuki H, Sawai Y, Suzuki T and Kawai K. 2003. Purification and characterization of an extracellular beta agarase from Bacillus sp. MK03. J Biosci Bioeng $93,456-463$.

Thompson JD, Higgins DG and Gibson TJ. 1994. CLUSTALW: Improving the sensitivity of progresssive multiple sequence alignment through sequence weight-ing, position-specific gap penalties and weight matrix choice. Nucl Acid Res 22, 4673-4680.

Van der Meulen HJ and Harder W. 1975. Production and characterization of the agarase of Cytoplaga flevensis. Antonie van Leeuwenhoek 41, 431-447.

Vera J, Alvarez R, Murano E, Slebe JC and Leon O. 1998. Identification of a marine agarolytic pseudoalteromonas isolate and characterization of its extra cellular agarase. Appl Environ Microbiol 64, 4378-4383.

Wang J, Mou H, Jiang X and Guan H. 2006. Characterization of a novel beta-agarase from marine Alteromonas sp. SY37-12 and its degrading products. Appl Microbiol Biotechnol 71, 833-839.

Xue CH, Fang Y, Lin H, Chen L, Zhao-Jie L, Deng D and Xiao LC. 2001. Chemical characters and antioxidative properties of sulfated polysaccharides from Laminaria japonica. J Appl Phycol 13, 67-70.

Yoshizawa Y, Ametani A, Tsunehiro J, Nomura K, Itoh M, Fukui $F$ and Kaminogawa S. 1995. Macrophage stimulation activity of the polysaccharide fraction from a marine alga (Porphyra yezoensis): structurefunction relationships and improved solubility. Biosci Biotechnol Biochem 59, 1933-1937.

Young KS, Bhattacharjee SS and Yaphe W. 1978. Enzymic cleavage of the alpha-linkages in agarose, to yield agaro-oligosaccharides. Carbohydr Res 66, 207-211.

Zhang WW and Sun L. 2007. Cloning, characterization, and molecular application of a beta-agarase gene from Vibrio sp. strain V134. Appl Environ Microbiol 73, 2825-2831.

(Received 4 January 2010; Revised 22 February 2010; Accepted 12 March 2010) 